\title{
Bioresorbable Photonics: Materials, Devices and Applications
}

\author{
Xiaozhong $W^{1}$ and Qinglei Guo ${ }^{1,2,3, *}$ \\ 1 Center of Nanoelectronics, School of Microelectronics, Shandong University, Jinan 250100, China; \\ 202012434@mail.sdu.edu.cn \\ 2 State Key Laboratory of ASIC and Systems, Fudan University, Shanghai 200433, China \\ 3 State Key Laboratory of Functional Materials for Informatics, Shanghai Institute of Microsystem \\ and Information Technology, Chinese Academy of Sciences, Shanghai 200050, China \\ * Correspondence: qlguo@sdu.edu.cn
}

Citation: Wu, X.; Guo, Q.

Bioresorbable Photonics: Materials,

Devices and Applications. Photonics 2021, 8, 235. https://doi.org/

$10.3390 /$ photonics 8070235

Received: 25 May 2021

Accepted: 23 June 2021

Published: 25 June 2021

Publisher's Note: MDPI stays neutral with regard to jurisdictional claims in published maps and institutional affiliations.

Copyright: (c) 2021 by the authors. Licensee MDPI, Basel, Switzerland. This article is an open access article distributed under the terms and conditions of the Creative Commons Attribution (CC BY) license (https:// creativecommons.org/licenses/by/ $4.0 /)$.

\begin{abstract}
Bio-photonic devices that utilize the interaction between light and biological substances have been emerging as an important tool for clinical diagnosis and/or therapy. At the same time, implanted biodegradable photonic devices can be disintegrated and resorbed after a predefined operational period, thus avoiding the risk and cost associated with the secondary surgical extraction. In this paper, the recent progress on biodegradable photonics is reviewed, with a focus on material strategies, device architectures and their biomedical applications. We begin with a brief introduction of biodegradable photonics, followed by the material strategies for constructing biodegradable photonic devices. Then, various types of biodegradable photonic devices with different functionalities are described. After that, several demonstration examples for applications in intracranial pressure monitoring, biochemical sensing and drug delivery are presented, revealing the great potential of biodegradable photonics in the monitoring of human health status and the treatment of human diseases. We then conclude with the summary of this field, as well as current challenges and possible future directions.
\end{abstract}

Keywords: biodegradable photonics; biodegradable materials; optoelectronic devices; biomedical applications

\section{Introduction}

With the rapid development of material science, device architectures, micro/nano fabrication technologies and integration strategies, bioimplantable electronic devices or systems have gradually become important platforms for diagnosing and/or treating human diseases [1]. The abilities of delivering and receipting electrical signals form the basis of these devices, that can either allow for the monitoring of physiological information, including biophysical, biochemical and biopotential signals, or serve as electronic medicines to treat human diseases [2]. In the modern biomedical field, bioimplantable electronic devices are playing a more and more important role and developing towards the directions of high-performance, low-cost, miniaturization, multiple functionalities and good biocompatibility. As a result, various functional bioimplantable electronic devices that form the interface between biological substances and external instruments have been developed for biomedical applications, such as intracranial pressure detection [3], Parkinson's symptom monitoring [4,5], drug delivery [6] and biomolecular level detection [7,8], as well as the most widely used cardiac pacemakers and glucose meters [9]. Although great successes have been achieved, challenges of bioimplantable electronics mainly lie in possible side-effects induced by electrical stimulations, susceptible performances, due to the electromagnetic interference in clinical circumstances and effective approaches to supply electrical power, and the requirement of complex and expensive instruments.

As an alternative option, bioimplantable photonic/optical devices that utilize the interaction between light and biological substances are of great appeal, due to their robust 
performance against internal/external interferences [10], fewer side effects on biotissue and the elimination of high-cost instruments [11]. In the biomedical field, light signals can locally stimulate specific cells and simultaneously explore their temporal dynamics to reveal the physiological process of cells [12]. In this way, clinical diagnosis and/or therapy of human diseases at macro or micro scales can be realized [13]. Demonstration examples include phototherapy [14-16], photobiomodulation [17,18], biosensors (temperature and pressure, etc.) [10], biomolecule detection [19,20], fluorescence bioimaging [21-23], optogenetics [24,25] and many others. Due to the particularity of human implantation, these bioimplantable photonic/optical devices are required to be biocompatible and miniaturized, thus allowing for the noninvasive implantation, as well as the minimal damage to biotissue during their in vivo operation. However, after completing the clinical functions within the human body, these implanted photonic/optical devices need to be extracted through a secondary surgery, which will bring costs and risks to the patients. Therefore, it is highly demanded to develop new types of bioimplantable photonic/optical devices, similar to bioresorbable transient electronics, that can completely disappear by in vivo dissolution or metabolism after a predefined operational period [26-28], thus eliminating the secondary surgery for retrieval. To construct a bioresorbable photonic device or system, strategies for choosing appropriate bioresorbable materials [29-31], optimized designs of their structures to obtain high performances and suitable integrations for their future applications are required.

In this paper, we will review the recent progress on bioresorbable photonic devices and systems, with emphases on the material strategies, device architectures and their promising applications. We start with the discussions on the biocompatibility and biodegradability of suitable materials (including inorganic and organic materials) for the construction of bioresorbable photonics. Then, various bioresorbable optical components, as well as the key considerations associated with materials and device structures, are described, including optical waveguide, optical filter, photodetector, light-emitting diode (LED) and solar cell. These devices or their integrations form the basis of bioresorbable optical platforms that are promising for applications in the monitoring of intracranial pressure and temperature, biomolecular level detection, tumor imaging, phototherapy and optogenetics. Finally, we end with the summary of this emerging field, including future challenges and opportunities.

\section{Material Strategies for Bioresorbable Photonic Devices}

Bioresorbable photonic devices that rely on optical methods are suitable for biomedical applications because they are fast, accurate and have few side effects on patients. Prior to the implantation into the human body, materials that are utilized to fabricate bioresorbable photonic devices or systems should be biocompatible or even bioresorbable. Biocompatible materials can eliminate the toxic or immunological response when exposed to human body or biotissue, thus enabling the device to work normally at the implantation site without affecting the health status of the patient [32,33]. At the same time, bioresorbable materials provide new opportunities for implantable photonic platforms that undergo complete physical disintegration and chemical reaction within the human body, thereby avoiding the secondary surgery for retrieval.

To fabricate bioresorbable photonic devices, both inorganic and organic materials are suitable and the choice of appropriate materials is strongly dependent on their following application scenarios. Table 1 summarizes the commonly used materials and their roles served for the construction of bioresorbable photonic devices. For inorganic semiconductors (such as silicon, germanium and zinc oxide), they can serve as the active materials of optoelectronic devices, for example photodetectors, solar cells and LEDs [19,34,35]. Moreover, silicon can be utilized as optical waveguide that delivers light signals to human body or biotissue [20]. The commonly used inorganic insulators, such as silicon dioxide and silicon nitride, form the dielectronic materials or water/ion barrier layers of bioresorbable optoelectronic devices [36,37], as well as optical filters [19]. Bioresorbable metals that 
serve as electrodes include Mo, Mg, W, Zn, Fe [38,39]. For organic bioresorbable materials, including silk, agarose, hydrogel, poly(ethylene glycol) diacrylate (PEGDA), poly(L-lactic acid) (PLLA), poly(lactic-co-glycolic acid) (PLGA), cellulose and peptides, they can serve as either the substrate to support bioresorbable photonic device [40-46] or the encapsulation layer [47] to protect the device from the dissolution of the active materials. Moreover, the low cost and ease of manufacture facilitates the convenience to utilize some organic materials as bioresorbable optical fibers/waveguides, thus enabling the delivery of light into the biotissue [48-53]. In addition, the functionalization of organic materials leads to the modification of their physical or chemical properties. For example, Jurgensen et al. doped polyfluorene into peptide and the generated hybrids can serve as the active layer of an organic light-emitting diode (OLED) [46].

Another crucial consideration for selecting appropriate materials when constructing a bioresorbable photonic device lies in their biocompatibility, which can be evaluated by the in vitro and/or in vivo cytotoxicity. Taking silicon as an example, Hwang et al. performed both in vitro and in vivo tests to evaluate its toxicity [54]. In vitro cytotoxicity studies were performed by culturing metastatic breast cancer cells on silicon nanomembranes for consecutive days. After ten days, the cell viability still reached $93 \pm 4 \%$, indicating a good biocompatibility of silicon. Then, they carried out in vivo assessment of the toxicity of silicon by the implantation of silicon nanomembranes beneath the dorsal skin of a mice model. After five weeks, no cytotoxicity and no weight loss in the mice were demonstrated by using high-density polyethylene (HDPE) as the Food and Drug Administration (FDA)approved control material. Moreover, through the immunohistochemistry and hematoxylin and eosin (H\&E) staining of the skin sections, comparable level of immune cells to those of HDPE control groups were demonstrated. Similar in vitro or in vivo cytotoxicity tests can be performed to evaluate the toxicity and biocompatibility of the selected materials.

Table 1. Commonly used bioresorbable optical materials and their roles/applications for the construction of devices.

\begin{tabular}{|c|c|c|c|}
\hline Type & Materials & Roles/Applications & Ref. \\
\hline \multirow{4}{*}{ Inorganic materials } & $\mathrm{Si}$ & $\begin{array}{l}\text { Semiconductor } \\
\text { Optical waveguide }\end{array}$ & $\begin{array}{c}{[36,38,39]} \\
{[20]}\end{array}$ \\
\hline & $\mathrm{Ge}, \mathrm{ZnO}$ & Semiconductor & {$[34,55,56]$} \\
\hline & $\mathrm{SiO}_{2}, \mathrm{Si}_{3} \mathrm{~N}_{4}$ & $\begin{array}{l}\text { Optical filter } \\
\text { Insulator }\end{array}$ & $\begin{array}{c}{[19]} \\
{[36,37]}\end{array}$ \\
\hline & $\mathrm{Mo}, \mathrm{Mg}, \mathrm{W}, \mathrm{Zn}, \mathrm{Fe}$ & Conductor & {$[38,39,57]$} \\
\hline \multirow{10}{*}{ Organic materials } & \multirow{3}{*}{ Silk } & Substrate & {$[40,41]$} \\
\hline & & Optical waveguide & [49] \\
\hline & & Microprism & [21] \\
\hline & \multirow{2}{*}{ PLLA } & Encapsulation & [47] \\
\hline & & Optical waveguide & [51] \\
\hline & \multirow{2}{*}{ PLGA } & Substrate & {$[42,43]$} \\
\hline & & Optical waveguide & {$[51,52]$} \\
\hline & Peptide-polyfluorene & Active layer for OLED & [46] \\
\hline & Cellulose, Peptides & Substrate & [44-46] \\
\hline & Agarose, PEGDA, Hydrogel, PVP & Optical waveguide & {$[50,52,53]$} \\
\hline
\end{tabular}

In terms of implanted biomedical applications, one of the most significant challenge of bioresorbable photonic devices lies in the capability of controlling or defining the operation period within human body. Normally, the dissolution rate of the utilized materials determines the operation period within human body [58]. For bare bioresorbable devices that are implanted in the human body, rapid dissolution occurs when they contact with 
biotissue or biofluids, thus leading to the device failure. Therefore, the use of encapsulation layers that protect bioresorbable photonic devices from the exposure to biofluids brings about a prolonged operation period, which is required for the monitoring or treatment of chronic diseases. The selection of encapsulation materials is strongly determined by the required operation period of bioresorbable devices. For example, a dense $\mathrm{SiO}_{2}$ layer grown at high-temperature can largely prevent the penetration of biological fluids, thus providing a long-term protection (approaching 70 years for the thermally grown $\mathrm{SiO}_{2}$ with a thickness of $1 \mu \mathrm{m}$ ) against the dissolution [59]. Other materials, such as evaporated or deposited $\mathrm{SiO}_{2}$ and $\mathrm{Si}_{3} \mathrm{~N}_{4}$, organic bioresorbable polymers (PLLA, PLGA, etc.), or their hybrids, are suitable for encapsulating devices with a purpose of short-term operation period (days to weeks). Specially, bioresorbable polymers are of great convenience due to the simple fabrication method (spin-coating or drop-casting). Moreover, the lifetime or the degradation of the devices can be customized by using triggerable encapsulation layers [60]. Once triggered by the external stimuli, such as thermal heating, light exposure and electrothermal treatments, the transience of the device starts until its full degradation. Material strategies provide possibilities for the design of triggerable stimuli. For example, local temperature changes caused by the near-infrared radiation can accelerate the dissolution reaction of implanted devices [61]. Similar scheme, such as wirelessly electrical heat or optically triggered degradation, can also promote the failure and dissolution of the implanted devices [62,63].

\section{State-of-the-Art Bioresorbable Photonic Devices}

\subsection{Optical Waveguide}

Implantable optical waveguides that can transmit light to target tissues or other implanted optical devices have exhibited great potentials for biomedical applications [64-70]. Traditional optical waveguide has good optical properties, low transmission loss of light and can transmit lights to deep tissues or organs. However, its rigid and brittle mechanical properties and poor biocompatibility may lead to possible tissue lesions and rejection reaction when implanted into the human body [48,71,72]. For biomedical applications, an ideal implantable optical waveguide should have the following features: (i) excellent optical properties for efficiently delivering lights; (ii) good biocompatibility for eliminating the rejection reaction of patients; (iii) biodegradability, so that they can be dissolved and resorbed by the human body for avoiding the secondary surgery for retrieval. Therefore, various efforts have been devoted to developing material strategies and fabrication techniques to obtain high-performance bioresorbable optical waveguides. As summarized in Table 2, both inorganic and organic materials, which have different dissolution rates, have been employed for the fabrication of optical waveguides. Especially for silicon-based optical waveguides, they show high optical transparency [48]. Bai et al. demonstrated a transient optical waveguide fabricated with monocrystalline silicon [20], as shown in Figure 1a. Monocrystalline silicon filaments encapsulated with PLGA form the flexible transient optical waveguide, which enables accurate light transmission, as shown in the bottom panel of Figure 1a. Moreover, the detection of the local light transmission spectrum at the implant site enables the assessment of biochemistry. The dissolution of the demonstrated silicon waveguide appears in Figure 1b. After the immersion in phosphate buffer saline (PBS) for 10 days, silicon waveguide can be completely dissolved. Podrazky et al. utilized phosphate glass fiber as the bioresorbable optical waveguide [73], as shown in Figure 1c. The phosphate-based optical fiber has good transparency and its solubility in water can be adjusted by changing the chemical composition to meet the requirements on the operation period. The following in vivo assessment on the toxicity of phosphate glass-based optical fibers evidenced their excellent biocompatibility. 
Table 2. Optical loss and degradation rate of common biodegradable optical waveguides.

\begin{tabular}{|c|c|c|c|c|}
\hline Materials & Dimensions & Optical Loss & Degradation Rate & Ref. \\
\hline $\mathrm{Si}$ & $\begin{array}{l}\text { width: } 50 \mu \mathrm{m} ; \\
\text { thickness: } 1.5 \mu \mathrm{m}\end{array}$ & $\begin{array}{l}0.7 \mathrm{~dB} / \mathrm{cm} \\
(1550 \mathrm{~nm})\end{array}$ & $\begin{array}{c}\text { P-type (boron), } 5 \mathrm{~nm} / \text { day and } \\
140 \mathrm{~nm} / \text { day in PBS at } 37 \text { and } \\
67^{\circ} \mathrm{C} \text {, respectively. }\end{array}$ & [20] \\
\hline Phosphate-based & $\begin{array}{c}50 \mu \mathrm{m} \\
\text { (diameter) }\end{array}$ & $\begin{array}{l}7 \mathrm{~dB} / \mathrm{m} \\
(1300 \mathrm{~nm})\end{array}$ & $\begin{array}{c}1.4 \mu \mathrm{m} \text { / day for refreshed solution } \\
\text { and } 0.4 \mu \mathrm{m} / \text { day for the same solution } \\
\text { kept for a month. (PBS, RT) }\end{array}$ & [73] \\
\hline PLLA & $\begin{array}{c}220 \mu \mathrm{m} \\
\text { (diameter) }\end{array}$ & $\begin{array}{c}1.64 \mathrm{~dB} / \mathrm{cm} \\
(473 \mathrm{~nm})\end{array}$ & $\begin{array}{l}\text { Fully degradation could take } \\
\text { one to two years. }\end{array}$ & [51] \\
\hline PLGA (50:50) & - & - & Fully dissolve in vivo within 1 month & [52] \\
\hline PVP & - & - & Fully dissolves in vivo within $1 \mathrm{~h}$. & [52] \\
\hline Silk & $\begin{array}{l}\text { width: } 2.9 \mathrm{~mm} \text {, } \\
\text { thickness: } 40 \mu \mathrm{m}\end{array}$ & $\begin{array}{l}2.0 \mathrm{~dB} / \mathrm{cm} \\
(540 \mathrm{~nm})\end{array}$ & - & [49] \\
\hline Agarose-based & $\begin{array}{l}0.64 \mathrm{~mm} \text { core, } \\
2.5 \mathrm{~mm} \text { cladding } \\
\text { (diameter) }\end{array}$ & $\begin{array}{l}3.23 \mathrm{~dB} / \mathrm{cm} \\
(633 \mathrm{~nm})\end{array}$ & - & [50] \\
\hline
\end{tabular}
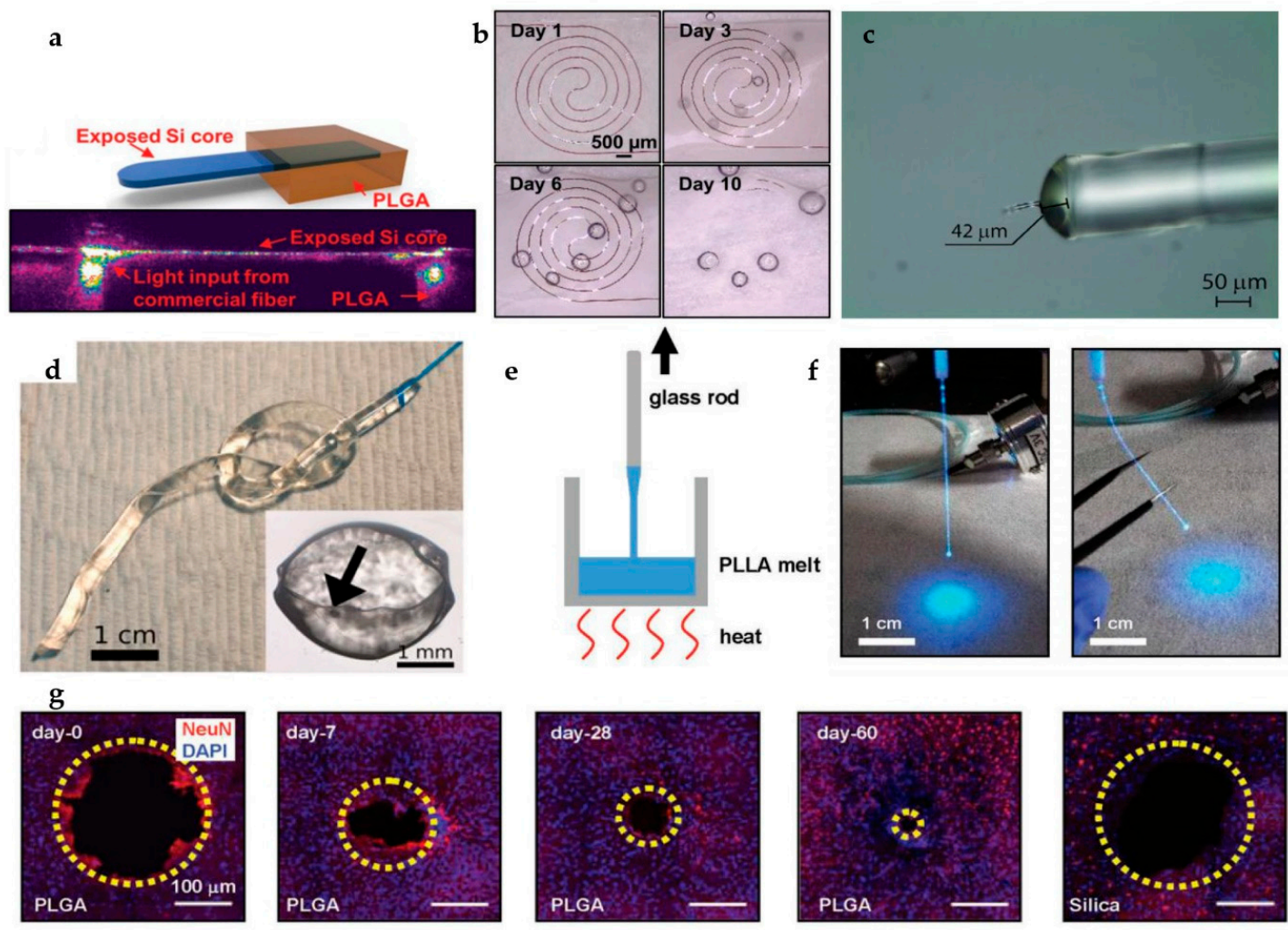

Figure 1. (a) Schematic illustration of a silicon nanomembrane-based optical waveguide encapsulated with PLGA (top) and optical image of the silicon nanomembrane-based optical waveguide (bottom). (b) Optical image of the dissolution process of a typical silicon-based optical waveguide in PBS at $\left.70^{\circ} \mathrm{C}\right)$. (a,b) Reproduced with permission from [20]. (c) Optical image of a phosphate glass-based optical fiber. Reproduced with permission from [73]. (d) Optical photographs of a silk-based optical fiber. Reproduced with permission from [49]. (e) Schematic illustration of the fabrication process of PLLA-based optical fibers. (f) Optical images of a PLLA fiber that transmits light at straight (left) and bending (right) states. (g) Time scale dissolution process of a PLGA-based optical waveguide in PBS $\left(\mathrm{pH}=7.4,37^{\circ} \mathrm{C}\right)$. The dissolution of a PLLA fiber reduces the areas of lesion (highlighted with yellow dotted circle). The right panel shows a silica-based waveguide implanted into a brain at the same conditions as a comparison. (e-g) Reproduced with permission from [51]. 
The biodegradable polymer-based optical waveguides often have better flexibility than that of inorganic optical fibers. Natural polymers, such as silk protein fibers (Figure 1d) [49] and agaroses [50], can serve as promising candidates for the fabrication of biocompatible and bioresorbable optical waveguides. For synthetic polymers, for example PLLA, bioresorbable optical waveguides can be simply achieved by the thermal drawing process [51], as illustrated in Figure 1e. The obtained PLLA-based optical fiber, with a diameter of $220 \mu \mathrm{m}$, can be linked to external light sources, as shown in Figure 1f. Moreover, PLLA-based optical fiber shows high flexibility compared to traditional fused silica fibers with the same geometries because of its low stiffness (about $1.5 \times 10^{4} \mathrm{~N} \mathrm{~m}^{-1}$ ) [51]. In vivo brain function tests, including neural signal sensing and optogenetic experiments, were performed by utilizing these bioresorbable PLLA optical fibers. Other organic materials, such as PLGA [51], Poly(vinylpyrrolidinone) (PVP) [52] and PEGDA [53], can be also used to fabricate bioresorbable optical waveguides. As an example, Figure $1 \mathrm{~g}$ shows the in vivo biodegradation tests of PLGA fibers in the brains of multiple mice [51]. The authors demonstrated that PLGA optical fibers can fully dissolve after the implantation for two weeks. Unlike the traditional silica fiber (see the right panel of Figure $1 \mathrm{~g}$ ), that has poor degradability, the lesions in the brain generated by the complete dissolution of PLGA fiber can be gradually reduced and recovered after 60 days. Table 2 shows the optical loss and degradation rates of some common bioresorbable optical waveguides fabricated with different materials. As an important component, these developed bioresorbable optical waveguides pave the way for the applications of bioimplantable photonic systems in biomedical engineering.

\subsection{Optical Filter}

Optical filters, that can selectively transmit or reflect lights with a specific wavelength, are known as a key component of photonic systems and have been widely used in various fields [74-76]. Conventional filters are typically deposited on rigid substrates, which may bring local damage of biotissue when implanted into the human body. In addition, high temperature during the deposition are incompatible with many flexible substrates [77]. Recently, advanced assembly methods based on transfer printing have been developed to provide a powerful solution for the integration of high-performance optical filters onto a variety of unconventional substrates [78]. After the deposition of the filter layer on silicon or glass substrates, the transfer printing technique [79-82] was utilized to transfer these filter layers onto flexible substrate. The obtained optical filter exhibited good flexibility and high optical performances, with almost unaffected characteristics after bending. This transfer method provides a new idea for the fabrication of high-performance optical filters on flexible substrates.

In terms of bioimplantable photonics [83-85], bioresorbable optical filters are also available via the appropriate choice of materials. For example, Bai et al. utilized multiple layers of silicon oxide $\left(\mathrm{SiO}_{\mathrm{x}}\right)$ and silicon nitride $\left(\mathrm{SiN}_{\mathrm{y}}\right)$ to fabricate transient optical filters [19]. Specially, alternate $\mathrm{SiO}_{\mathrm{x}}$ and $\mathrm{SiN}_{\mathrm{y}}$ layers were deposited on silicon substrates using plasma enhanced chemical vapor deposition (PECVD). The multilayer film was then transferred to PLGA substrates, forming the bioabsorbable optical filter. Moreover, through the tune of the number and thickness of $\mathrm{SiO}_{\mathrm{x}}$ and $\mathrm{SiN}_{\mathrm{y}}$ film pairs, the obtained bioabsorbable optical filters have controllable filtration features, including band-stop range and optical density [19]. Lu et al. took advantage of the interference in free-standing singlecrystalline silicon nanomembranes to fabricate bioresorbable optical filters [35]. Through changing the thickness of the silicon nanomembrane on PLGA, controllable transmission of red (R), green-yellow (G), or blue-violet (B) lights is available, as shown in Figure 2a. The following placement of these bioresorbable optical filters (determined by the thickness of silicon nanomembrane, i.e., $42 \mathrm{~nm}, 62 \mathrm{~nm}$ and $85 \mathrm{~nm}$ ) on the top of a LED allowed the selective transmission of $R, G$, or $B$ light, as shown in Figure $2 b$. These demonstrated results address the barriers between the flexibility and high performances of optical filters and also 
provide feasible pathways to fabricate bioresorbable optical filters for use in bioimplantable photonic systems.

a

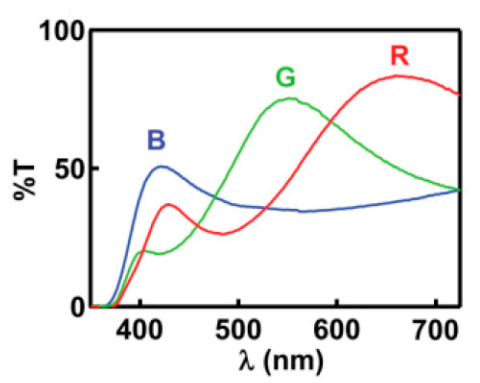

b

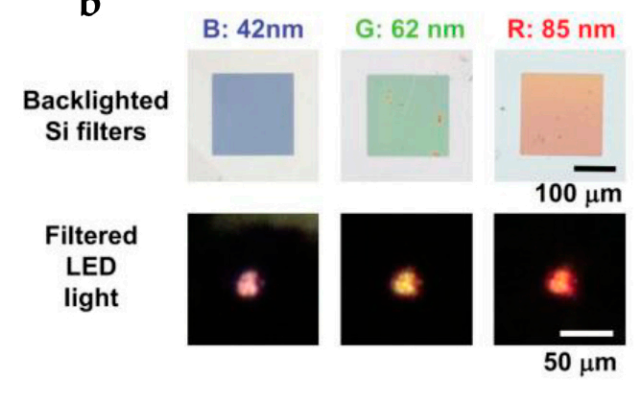

Figure 2. (a) Transmission spectra of different bioresorbable optical filters based on single-crystalline silicon nanomembranes. (b) Optical images of the bioresorbable optical filters and the filtered light from the integration of filters and LEDs. (a,b) Reproduced with permission from [35].

\subsection{Photodetector}

The photodetector is known as a device that can convert optical signals into electrical signals. As a result, the irradiated light intensity or light spectrum can be accessed via photodetectors. In terms of their applications in biomedical engineering, photodetectors can either prevent the over exposure of light to biotissue, which may cause apoptosis or damage to the mitochondrial membrane potential [86,87], or provide diagnosis of human health status. In recent years, efforts have been made to develop bioinspired photodetectors with high conversion efficiency, mechanical flexibility and biocompatibility [44,45]. Nevertheless, most of the developed photodetectors are partially degradable. For example, Kopeinik et al. developed an organic photodiode based on wood pulp fiber networks [44]. The device showed obvious rectification characteristics under the dark condition and significant photovoltaic behavior under illumination. The good biocompatibility and degradability of the utilized cellulose in their work may provide opportunities for the development of implantable optoelectronic devices. More recently, Bai et al. developed silicon-based fully bioresorbable tri-color photodetectors [19]. The authors utilized a silicon membrane as the active material, designed vertical stacks of three PN junctions and used the transfer printing technique to integrate the photodetector on PLGA substrate. Because the penetration depth of light varies with the wavelength, the spectroscopic characterization of physiological status and neural activity is available by the fabricated tri-color photodetectors, which will be discussed later. Although bioresorbable photodetectors play an important role in photonic devices for biomedical applications, related studies are still rare. Future opportunities exist in the combination of material strategies, device architectures and fabrication techniques to obtain high-performance and wide-band bioresorbable photodetectors.

\subsection{LED}

A fully bioimplantable and bioresorbable photonic/optical system that utilizes the interaction between light and biotissue provides numerous opportunities in diagnostic and therapeutic functions for biomedical applications. As a result, a bioresorbable LED that acts as the light source for the system is urgently demanded. Although III-V semiconductor-based LEDs are the most attractive candidates for solid-state light emitters, III-V semiconductors are normally toxic and undegradable. Utilizing biocompatible dielectrics as the encapsulation layer may provide opportunities for III-V LEDs for applications in biomedical implants. However, the secondary surgery is still necessary to remove the implanted LED from the human body. Recently, many LEDs fabricated with biocompatible or biodegradable organic molecules and polymers, with low Young's modulus, have been reported $[88,89]$. For example, Jurgensen et al. reported the utilization of the 
riboflavin-derived biomaterial riboflavin tetrabutyrate for the fabrication of OLEDs [90], which yielded an orange exciplex emission (640 $\mathrm{nm}$ in wavelength) with a maximum luminance of $10 \mathrm{~cd} / \mathrm{m}^{2}$ and an external efficiency of $0.002 \%$. Khanra et al. demonstrated a biodegradable OLED by utilizing the diphenylalanine/polyfluorene nanocomposites [46], in which the polyfluorene served as the blue-emitting conducting polymers. A significant light emission, at $435 \mathrm{~nm}$, was demonstrated. Although significant progress has been achieved, OLEDs are very sensitive to water and oxidizing agents [91], thus affecting their optoelectronic performances.

More recently, $\mathrm{Lu}$ et al. demonstrated a bioresorbable transient LED, consisting of a hybrid of II-VI semiconductor (zinc oxide, $\mathrm{ZnO}$ ) and silicon and an ultra-thin bioresorbable transparent electrode (molybdenum, Mo, $8 \mathrm{~nm}$ in thick) [35], as shown in Figure 3a. All utilized materials are inorganic, biocompatible and bioresorbable. Specially, the authors utilized silicon as the "p-type material" to overcome the difficulty in growing high-quality $\mathrm{ZnO}$ based PN junctions, allowing the injection of holes from the silicon side. As a result, a maximum light power density of $0.7 \mathrm{~mW} / \mathrm{cm}^{2}$ at $9 \mathrm{~V}$, with a wide-range of visible wavelengths, was obtained, as demonstrated in Figure 3b,c. The integration of bioresorbable silicon-based optical filters on LEDs also allowed narrow emission profiles at selective wavelengths [35]. These presented results provide a practical approach to fabricate bioresorbable light sources, thus paving the way for the development of transient electronic/optoelectronic systems.

a

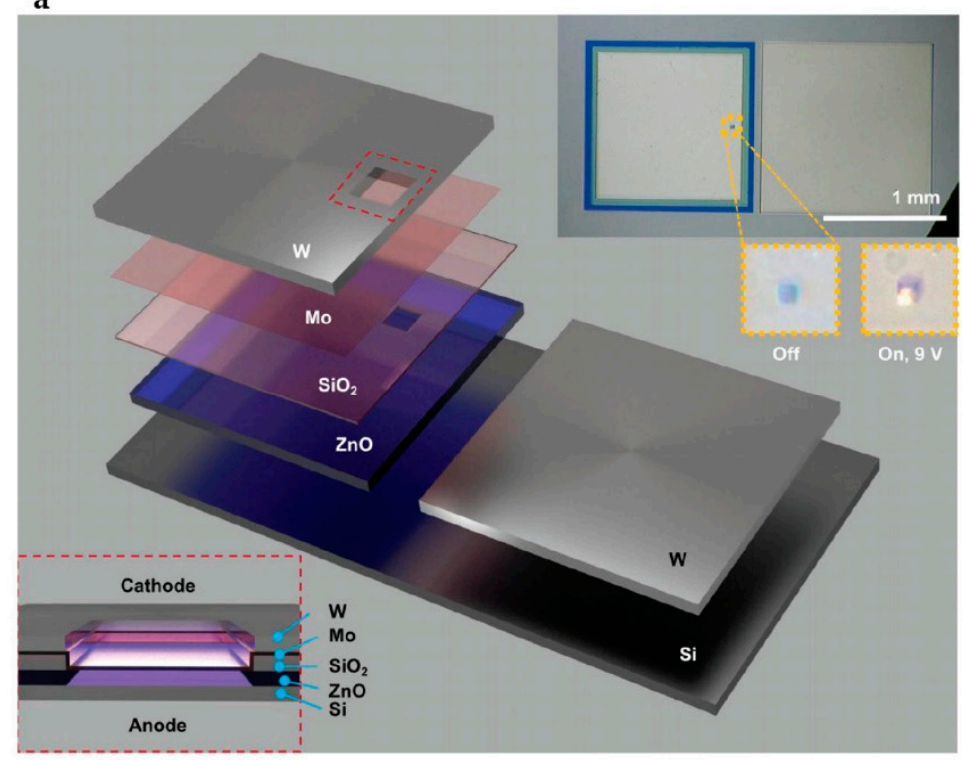

b

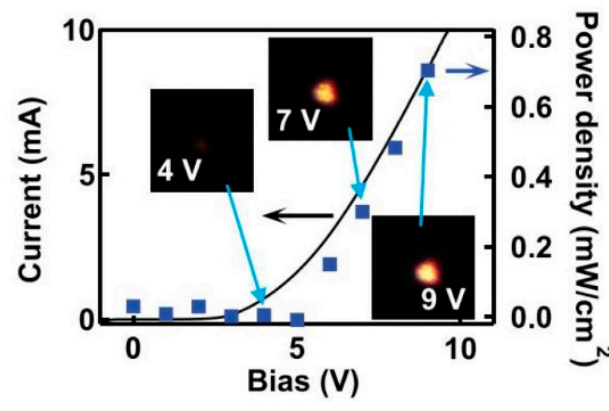

c

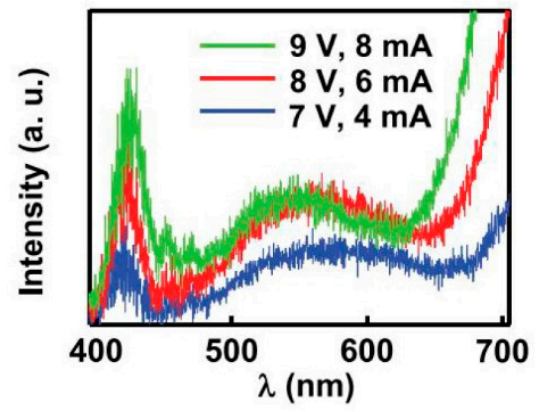

Figure 3. (a) Materials and structure diagram of the fully biodegradable LED fabricated with inorganic materials. (b) Light intensity of the demonstrated biodegradable LED under different bias voltages. (c) Emission spectra of the demonstrated biodegradable LED under different bias voltages. (a-c) Reproduced with permission from [35].

\subsection{Solar Cell}

Similar to implantable transient electronic devices or systems, bioresorbable photonics, especially for the active components or their integrations, also require the electrical power supply for the operation. Therefore, a fully bioresorbable power supply device that can deliver enough electrical power is demanded. Attractive candidates include bioresorbable batteries [92], supercapacitors [93], triboelectric nanogenerators [94], piezoelectric harvesters [95], inductive coupling devices [96] and magnetically coupled power supply devices [97]. As an alternative choice, bioresorbable transient solar cells are also developed for supplying electrical power. Although they normally have a limited implantation depth (determined by the penetration depth of the illuminated light in biotissue) 
compared to other bioresorbable power sources, bioresorbable transient solar cells with appropriate material strategies will enable a long-term energy supply and a high output power density $[98,99]$.

Due to the mature manufacturing process of silicon-based semiconductor technology and the large amount of silicon on earth, silicon-based solar cells have been dominant in all kinds of solar cells. In the field of implantable medicine, flexible, bioabsorbable silicon photovoltaic cells hold great promise for power supply [100].

Figure 4a schematically demonstrates a fully degradable thin film amorphous silicon solar cell, consisting of biodegradable metal electrodes $(\mathrm{Mg})$, transparent conductive oxide $(\mathrm{ZnO})$, dielectric layers and other necessary layers [55]. The solar cells that use biodegradable metal electrodes exhibit similar performances compared to the devices with non-transient electrodes, as shown in Figure $4 \mathrm{~b}$. Notably, the use of SnO:F as the transparent conductive oxide layer has enhanced the performance of cells, which results from the improved conductivity and the management of the backscattered light. Figure $4 \mathrm{c}$ shows the performance of a fully degradable thin film amorphous silicon solar cell during hydrolysis in deionized water at room temperature. As the dissolution proceeds, the open-circuit voltage rapidly decreases, while the short current persists even after the full degradation of $\mathrm{Mg}$, because of the conduction through the transparent conductive oxide $(\mathrm{ZnO})$. However, the limitation of the above amorphous silicon-based biodegradable solar cell exists in the lack of photoelectric efficiency and the rapid transience (several hours) in an aqueous environment.

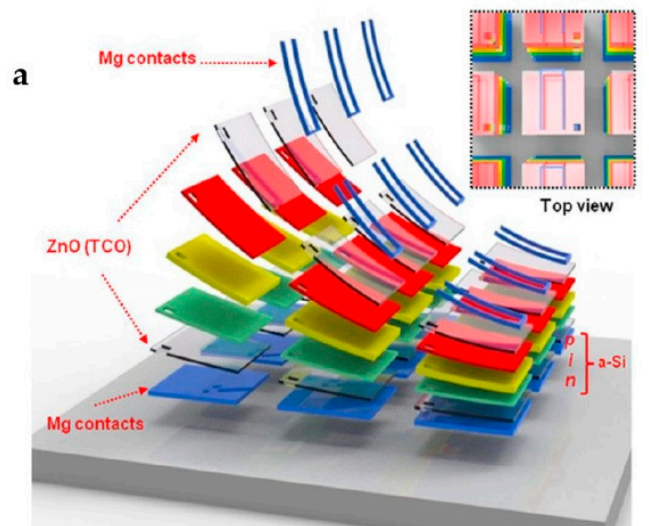

b

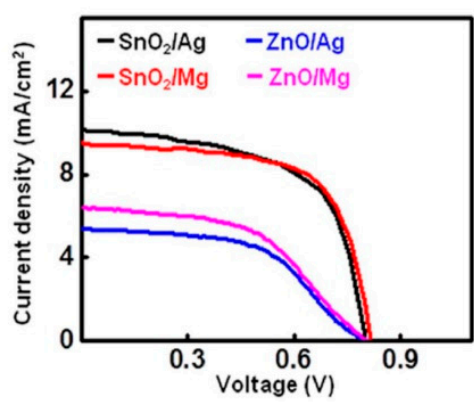

e

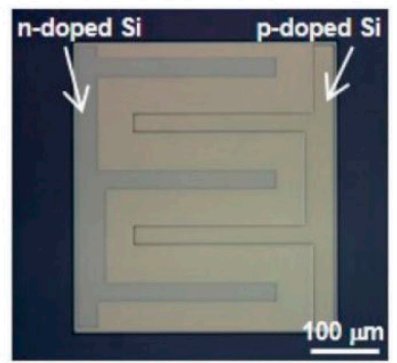

c
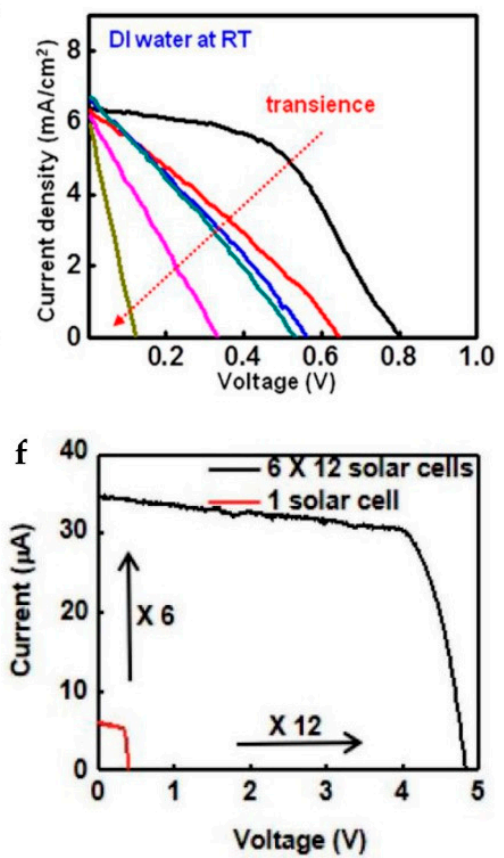

Figure 4. (a) Schematic diagram of key materials and structures of biodegradable transient solar cells. (b) Comparison of the current/voltage characteristics from a transient amorphous silicon-based solar cell and a nontransient amorphous silicon-based solar cell. (c) Current/voltage characteristics of a photovoltaic cell in deionized water at room temperature, revealing its transience behavior. (a-c) Reproduced with permission from [55]. (d) Optical image of a monocrystalline silicon photovoltaic cell array. (e) Optical microscope image of a single bioresorbable microcell. (f) Current/voltage characteristics of a single microcell (red) and an interconnected array (black). (d-f) Reproduced with permission from [34].

Lu et al. developed a fully biodegradable photovoltaic (PV) cell platform based on monocrystalline silicon [34], which has high photoelectric efficiency. A single cell appears 
in Figure 4e. The integration of $6 \times 12$ cells to form a PV array will enhance either the open-circuit voltage or the short current, as demonstrated in Figure $4 \mathrm{f}$. The PV array is designed for the wavelength (red and near-infrared) with a long penetration depth in biotissue, thus enabling enough illumination. After three days of the implantation, the bioresorbable PV array still had the ability to power a blue LED, as shown in Figure $4 \mathrm{~d}$. The bioresorbable PV system completely dissolved after 4 months and did not cause an inflammatory response.

Advanced thin-film silicon photovoltaic cells, as the bioresorbable power supply component, have promising application prospects in the field of biomedical engineering. Future researches should focus on achieving higher conversion efficiency with low cost or exploring more photovoltaic materials. In addition, advanced integration approaches are appealed to combine bioresorbable solar cells with other optical elements or circuits, such as light sources, waveguides, filters and various sensors, to form fully bioresorbable functional systems.

\section{Biomedical Applications of Bioresorbable Photonics}

Bioresorbable photonic/optical components or their integrations that utilize the interaction between light and biotissue provide opportunities for the diagnoses and/or treatment of human diseases [10-12]. This section will describe the applications of several implantable bioresorbable photonic/optical systems, such as intracranial temperature and pressure detection [10], biomolecular level detection $[19,20]$, photoimaging enhancement technology [21] and optogenetics and phototherapy [51,52].

\subsection{Intracranial Temperature and Pressure Sensor}

Intracranial pressure, temperature and other physical parameters are important basis that reflect the health status. During the clinical treatment, timely monitoring of temperature and pressure is an important means to formulate treatment plans and effectively treat human diseases. Here, bioresorbable sensors based on a Fabry-Perot interferometer and two-dimensional photonic crystal enable the continuous and accurate monitoring of pressure and temperature [10]. As schematically shown in Figure 5a, the bioresorbable pressure sensor consists of a stack of multiple layers, including thermal silicon oxide as the encapsulation layer for long-term operation, amorphous silica as the adhesion layer between silicon nanomembrane and silicon slab with a cavity and a Fabry-Perot interferometer (FPI). After the implantation into a rat skull, as shown in Figure 5b (sketched) and Figure 5c (optical image), the deflection of silicon nanomembranes caused by intracranial pressure results in the change of cavity thickness, thus leading to the change of formant position in the reflection spectrum. Therefore, the corresponding pressure can be obtained. Since temperature affects the refractive index of silicon, these platforms can also be configured as temperature-dependent sensors.

Figure $5 \mathrm{~d}$ schematically shows the integration of the bioresorbable FPI sensor and a PLGA optical fiber. Attributed to the extremely slow dissolution rate of thermal silicon oxide, the intracranial pressure (ICP) and temperature (ICT) sensors in rats can operate normally within 25 days. As shown in Figure 5e,f, changes in intracranial pressure or temperature alter the return loss spectra, with a significant shift in the peak wavelength. In addition, in vitro degradation processes and histopathological studies confirmed the biocompatibility and degradability of these integrated photonic systems. These presented results demonstrate the potential of the proposed bioresorbable photonic platform for not only the ICP and ICT sensors, but also the development of other types of bioresorbable photonic sensors. 
a

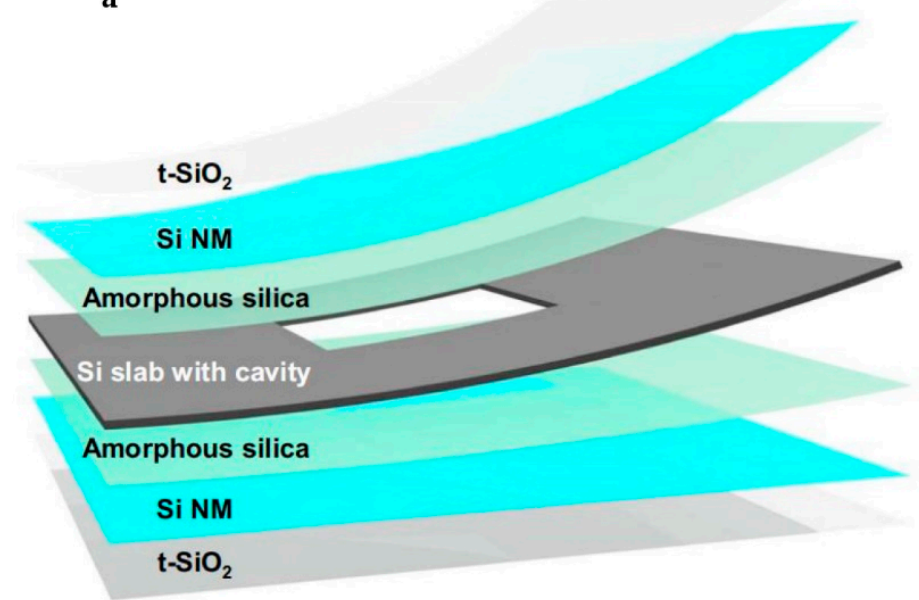

FP resonances in air and Si cavities
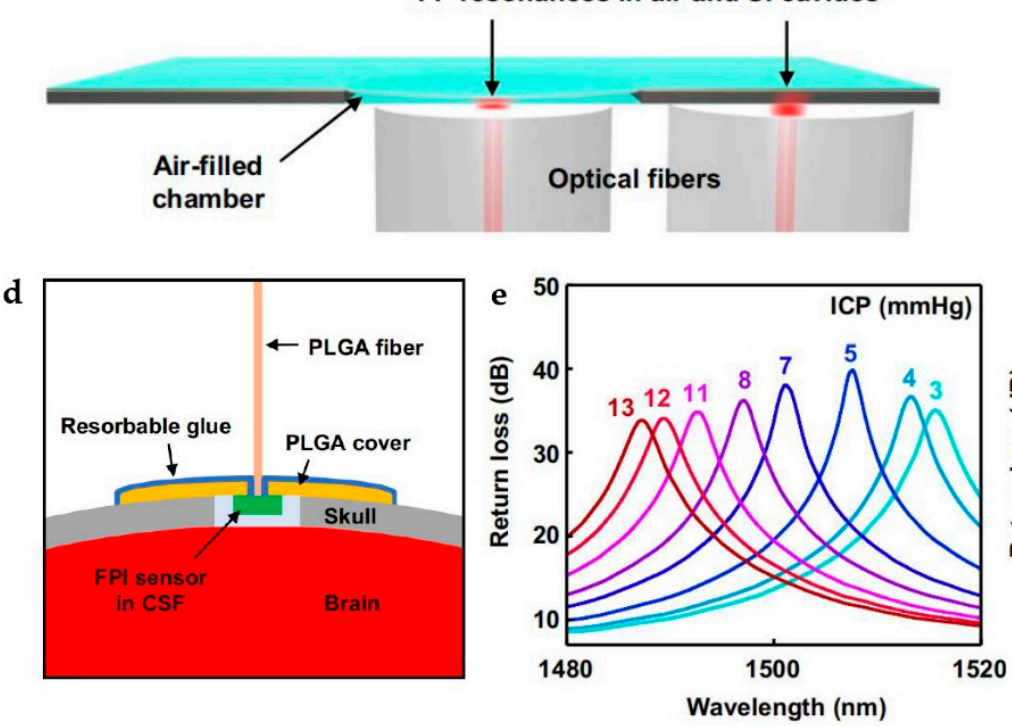

b

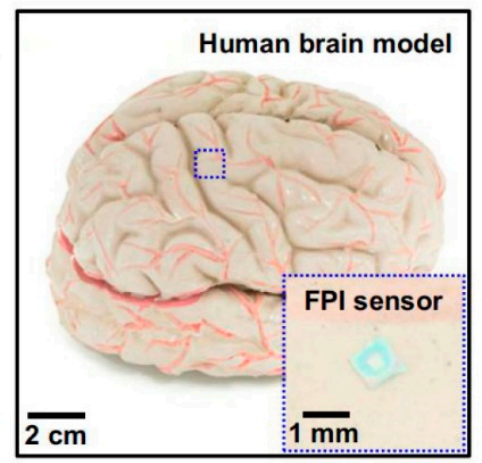

c
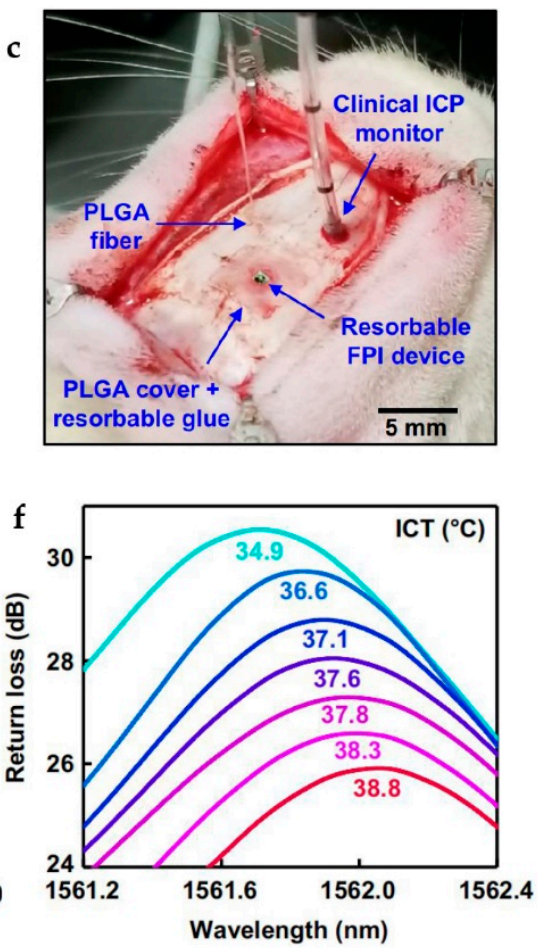

Figure 5. (a) Schematic illustration of the key materials and structures of a bioresorbable Fabry-Perot interferometer (FPI) pressure and temperature sensor. (b) Optical image of an FPI sensor placed on an adult brain model. A magnified view of the device appears in the inset. (c) Optical image of a bioresorbable FPI sensor implanted in the intracranial space of a rat for the monitoring of ICT and ICP. (d) Cross-sectional view of the configuration for devices and skull during animal testing. (e) Optical spectra obtained from a bioresorbable FPI pressure sensor under different pressure conditions. (f) Optical spectra obtained from a bioresorbable FPI temperature sensor at different temperatures. (a-f) Reproduced with permission from [10].

\subsection{Biomolecular Level Sensor}

The real-time monitoring of biochemical molecules, such as glucose, oxygen saturation, ethanol concentration and other related molecules, provides important information for evaluating and analyzing human health status. As a result, various bioresorbable photonic platforms with the capability of sensing biomolecules have been developed. Figure $6 \mathrm{a}, \mathrm{b}$ display a demonstration example that utilizes a silicon-based waveguide as the biosensor [20]. The operating principle is schematically illustrated at the bottom of Figure 6a. Continuous monitoring of blood oxygenation was enabled via the recorded transmission spectrum in the near-infrared range (1000-2000 nm). A similar demonstration via the proposed optical biosensor involves the optical sensing of glucose levels [20]. The study of important physiological information through near-infrared spectroscopy demonstrates the potential of these platforms in the biomedical field. Recently, the integration of biore- 
sorbable silicon-based photodetectors, $\mathrm{SiO}_{\mathrm{x}}$ and $\mathrm{SiN}_{\mathrm{y}}$ optical multilayer filters and PLGA waveguides that form a biomolecule detection system has been also developed [19]. After the implantation of the bioresorbable photonic system into the brains of free-moving mice, in vivo monitoring of intracranial temperature, brain oxygenation and neural activity were demonstrated. Moreover, the biodegradability of all utilized materials of each component in the system eliminates the secondary surgery for the removal of the equipment after use.
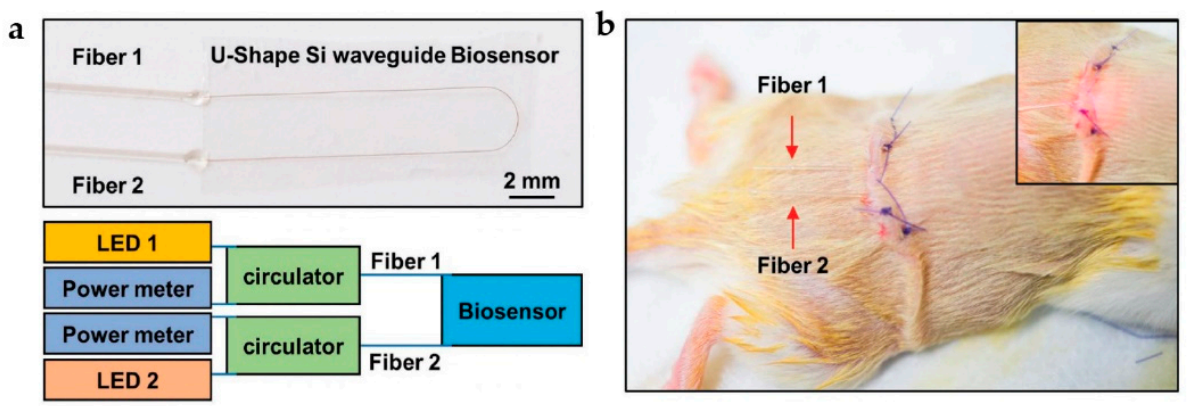

Figure 6. (a) Optical image of a transient silicon waveguide-based biosensor (top) and schematic illustration of the operating principles (bottom). (b) Optical image of a transient biosensor after the implantation into the subcutaneous region near the thoracic spine of a mouse model. The inset displays the optical image of a red light (wavelength: $660 \mathrm{~nm}$ ) passing through the biosensor. $(\mathbf{a}, \mathbf{b})$ Reproduced with permission from [20].

\subsection{Malignancy Imaging}

Advanced materials and fabrication techniques provide opportunities for the construction of high-quality micro-structured bioresorbable optical elements, which enable improved imaging of malignancies and treatment of malignant tumors. Recently, Tao et al. developed a multifunctional bioresorbable optical platform [21]. The authors utilized silk protein, known as a biocompatible, biodegradable and translucent biomaterial, to develop a free-standing two-dimensional microprism array, as shown in Figure 7a. When implanted into the target location, the microprism array can capture the forward-scattered photons that are normally lost in traditional reflection-based imaging techniques, thus enhancing the amount of light reflected to the detector. This allows for enhanced intrinsic sensitivity for the measurement over thicknesses, where dimensions normally exceed typical photon mean free paths. As a result, the signal for deep-tissue imaging, as well as the imaging contrast between the malignant tumor and the surrounding tissue, can be significantly enhanced. Figure $7 \mathrm{~b}$ schematically shows the experimental setup for the evaluation of the performance of a silk-based microprism array. Compared to a plain silk film, the presence of the microprism significantly enhances the reflected light signal, as demonstrated in Figure 7c. Further demonstrations involve covering the silk-based microprism array and unpatterned plain film with single or multiple layers of porcine fat with a thickness of $800 \mathrm{~mm}$ (Figure 7d) or with single or multiple layers of muscle tissue (Figure 7e). As a result, the presence of silk-based microprism reflector obviously enhances the intensity of the backscattered light in a wide-band range. The authors also performed both in vitro and in vivo tests to provide validation of the silk-based microprism array for improved imaging [21]. More importantly, the optical performance of the bioresorbable photonic platform degrades with the dissolution of the device, allowing for the real-time quantification of drug release, which provides disease treatment. These presented results conceptually demonstrate the potential of constructing a multifunctional bioresorbable photonic platform, which simultaneously provides treatment and information of disease progression. 


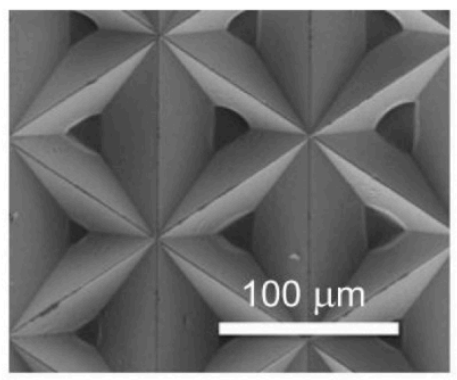

b

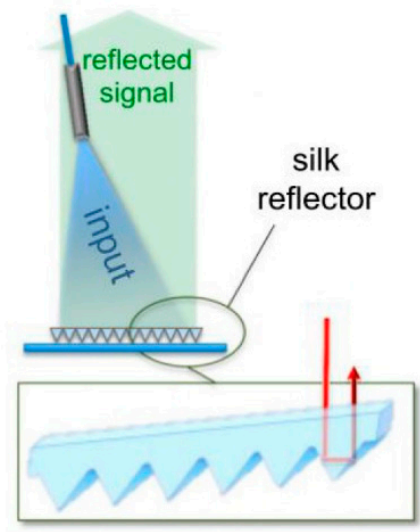

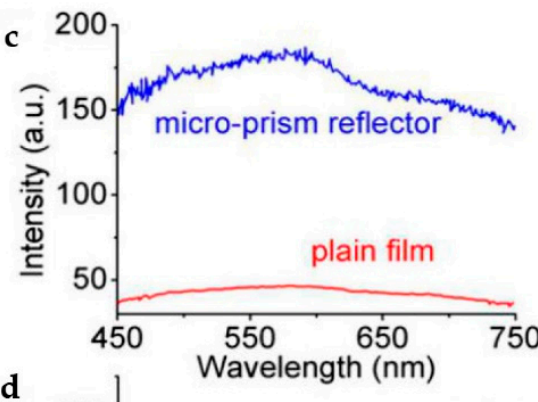
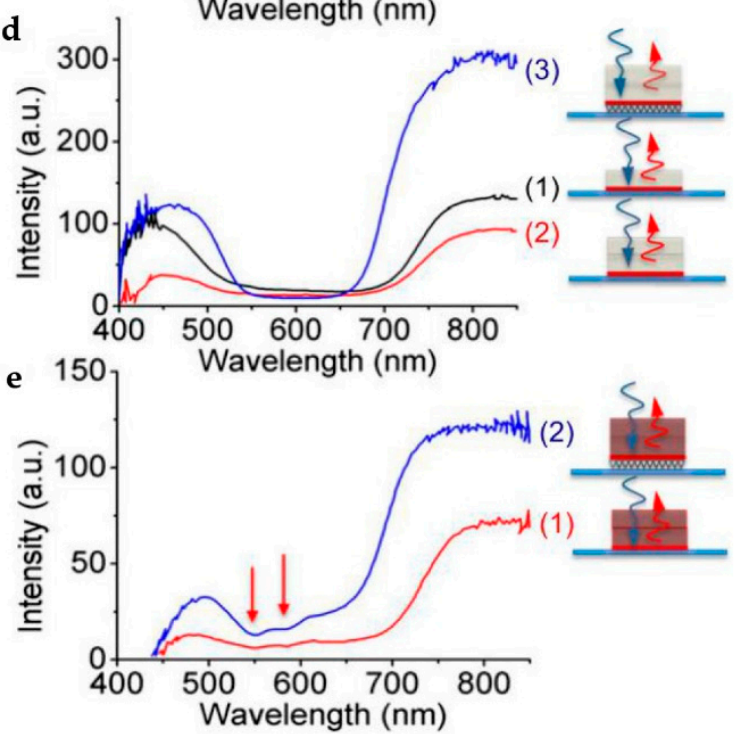

Figure 7. (a) Scanning electron microscope image of a typical silk microprism array. (b) Schematic illustration of the experimental setup for the measurement of the optical properties of the replicated microprism array. (c) Comparison of the reflected signal obtained from a microprism array (blue) and a plain silk film (red). (d) The reflected signals obtained from (1) a cellulose layer with red pigment covered with one layer of fat, (2) a cellulose layer with red pigment covered with two layers of fat and (3) a silk microprism array placing under a cellulose layer with red pigment covered with two layers of fat. (e) The reflected signals obtained from (1) a cellulose layer with red pigment covered with two layers of muscle tissue and (2) a silk microprism array placing under a cellulose layer with red pigment covered with two layers of muscle tissue. (a-e) Reproduced with permission from [21].

\subsection{Others}

Optogenetics that uses light-reactive proteins to stimulate neurons and to control emotions or behaviors of animals is a new technique in neuroscience. With optogenetics, people are able to pinpoint the relationship between specific neural circuits and brain function. In the past decade, optogenetics has exhibited great potentials in the treatment of depression [101], heart disease [102], Parkinson's symptoms [103], epilepsy [104] and many others. The optogenetic stimulation induced by the implantable and bioresorbable optical waveguides was also verified. Fu et al. infected the hypothalamus of a mice model with different viruses and studied the optogenetic stimulation of the hypothalamus [51]. As schematically illustrated in Figure 8a, the authors utilized AAV-DIO-oCHiEF-mCherry virus to specially inflect the excitatory neurons of the bilateral hyperactivating hippocampus of a CamkII-cre mice. The following optical stimulation through a bioresorbable optical fiber induced a mild seizure to the mice, with increased travelling distance and velocity. During the in vivo degradation of the optical fiber, the ability of inducing seizure weakened, because of the degraded performance of transmitting lights, as verified by the decreased travelling distance and velocity in Figure 8b,c. 
a
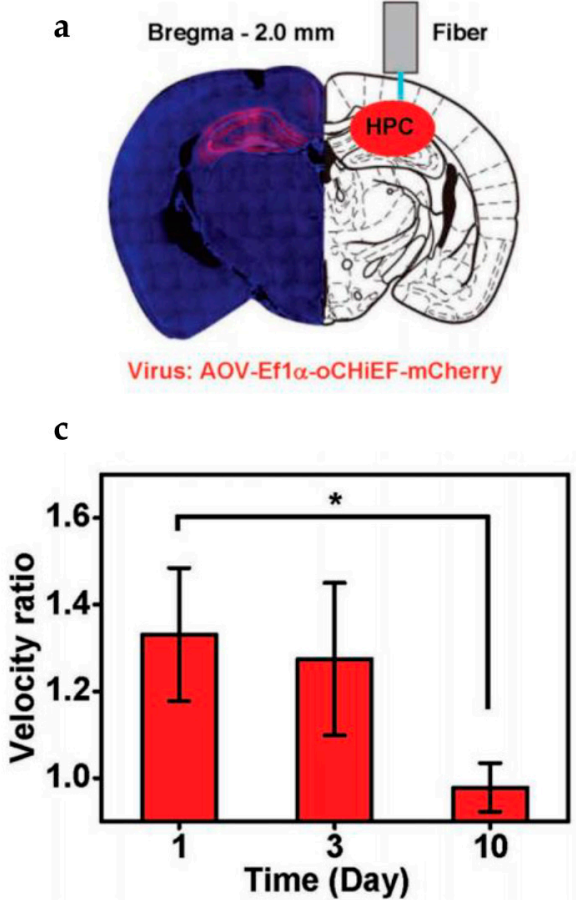

b

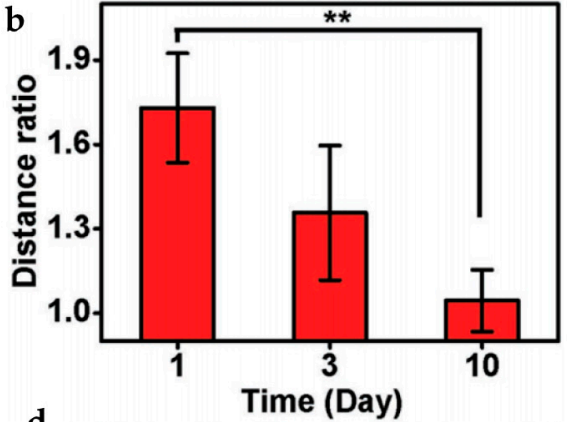

d

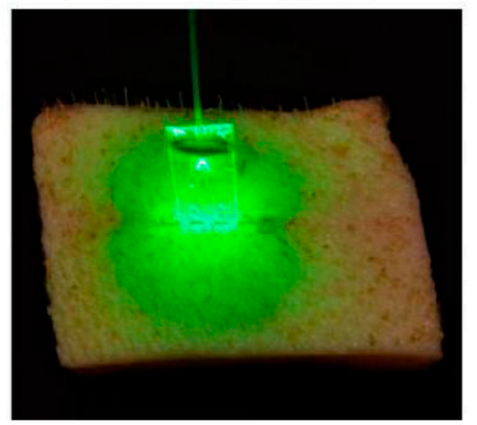

Figure 8. (a) Confocal microscope image obtained from a coronal section of a mice model containing enhanced green fluorescence protein two weeks after the viral transfection (left) and schematic diagram of a bioresorbable fiber that was implanted into the hippocampus (right). (b) The ratio of travelling distance with the laser on and off, varying with the in vivo dissolution of bioresorbable fibers. (c) The ratio of velocity with the laser on and off, varying with the in vivo dissolution of bioresorbable fibers. (a-c) Reproduced with permission from [51]. (d) Optical image of a porcine skin incision illuminated with an inserted waveguide by a green light to promote wound healing. Reproduced with permission from [52]. The symbols $\left(^{*}\right)$ in the bar chart are used to indicate the degree of difference, where "**" represents the significance probability $(p)<0.01$ and "** means $0.01<\mathrm{p}<0.05$.

In addition, light therapy that uses sunlight or artificial light to treat diseases and promote the recovery of human health status has been also developed via bioimplantable photonic/optical devices or systems, such as photodynamic therapy [105], photothermal therapy [106] and photobiological regulation [107,108]. In the case of targeted tumor therapy [105], drugs located near the targeted tumor can be released by photoactivation, thus inhibiting tumor activity. Another application scenario includes the photochemical tissue binding by utilizing bioresorbable optical waveguides. As shown in Figure $8 \mathrm{~d}$, optimal light delivery to the deep tissue is demonstrated [52]. As a result, a full thickness (>10 mm) wound closure of pig skin was achieved, suggesting a significant advantage over conventional surface illumination or non-biodegradable optical materials.

\section{Summary and Outlook}

The rapid development of material science and micro/nano-fabrication techniques has promoted the progress of implantable transient platforms for applications in biomedical engineering. As the alternatives, photonic/optical devices or systems that rely on the interaction between lights and biotissue are getting more and more attention. This paper reviews the recent progress on bioresorbable photonics, with emphases on material strategies, device architectures and integrations and their applications in biomedical engineering. To fabricate a bioresorbable photonic or optical device, both inorganic or organic materials are suitable, with the choice of materials depending on the required performance and following applications. Various bioresorbable optical components, including optical waveguide, filter, photodetector, LED and solar cells, with different functionalities have 
been demonstrated. The integration of these components, with appropriate substrates and encapsulation layers, will form a functional system, which exhibits significant potential for biomedical applications, including the diagnosis and treatment of human diseases.

Nevertheless, bioresorbable photonics is still in its infancy. Future opportunities in this area lie in many aspects, including the following: (i) developing new functional materials for the fabrication of high-performance bioresorbable photonic/optical devices; (ii) developing novel encapsulation strategies, including materials and structures, to control the operation period (from several days to weeks, months and even years) after the implantation; (iii) fabricating reliable bioresorbable light sources with high efficiency to activate the functional optical platform; (iv) fabricating reliable bioresorbable power supply devices to provide long-term and stable electrical energy to active optical components or systems; (v) extending the functionalities of bioresorbable photonic system, for example, with the capability of simultaneous diagnosis and treatment of human diseases; (vi) realizing or improving the wireless transmission of the sensed data or signals via bioresorbable photonic sensors. Possible approaches to address these issues include the optimization of material strategies, device structures, or the exploitation of a bioresorbable hybrid system that contains both electronic and photonic/optical components. These efforts will significantly promote the development of bioresorbable photonics, thus paving the way for their applications in biomedical engineering.

Author Contributions: X.W. and Q.G. contributed to the investigation, writing of original draft and reviewing of the manuscript. X.W. prepared the figures. Q.G. provided supervision. All authors have read and agreed to the published version of the manuscript.

Funding: This research was funded by the Qilu Young Scholar Program of Shandong University, the State Key Laboratory of ASIC and System (Grant No. 2020KF007), the State Key Laboratory of Functional Materials for Informatics (Grant No. SKL202101) and the Shandong University Multidisciplinary Research and Innovation Team of Young Scholars (No. 2020QNQT015).

Conflicts of Interest: The authors declare no conflict of interest.

\section{References}

1. Burton, A.; Obaid, S.N.; Vazquez-Guardado, A.; Schmit, M.B.; Stuart, T.; Cai, L.; Chen, Z.; Kandela, I.; Haney, C.R.; Waters, E.A.; et al. Wireless, battery-free subdermally implantable photometry systems for chronic re-cording of neural dynamics. Proc. Natl. Acad. Sci. USA 2020, 117, 2835-2845. [CrossRef]

2. Wang, X.J.; Feiner, R.; Luan, H.W.; Zhang, Q.H.; Zhao, S.W.; Zhang, Y.; Han, M.D.; Li, Y.; Sun, R.J.; Wang, H.L.; et al. Three-dimensional electronic scaf-folds for monitoring and regulation of multifunctional hybrid tissues. Extrem. Mech. Lett. 2020, 35, 100634. [CrossRef]

3. Yang, Q.; Lee, S.; Xue, Y.; Yan, Y.; Liu, T.; Kang, S.; Lee, Y.J.; Lee, S.H.; Seo, M.; Lu, D.; et al. Materials, Mechanics Designs, and Bioresorbable Multisensor Platforms for Pressure Monitoring in the Intracranial Space. Adv. Funct. Mater. 2020, $30,1910718$. [CrossRef]

4. Shawen, N.; O’Brien, M.K.; Venkatesan, S.; Lonini, L.; Simuni, T.; Hamilton, J.L.; Ghaffari, R.; Rogers, J.A.; Jayaraman, A. Role of data measurement characteristics in the accurate detection of Parkinson's disease symptoms using wearable sensors. J. Neuroeng. Rehabil. 2020, 17, 1-14. [CrossRef]

5. Benabid, A.L.; Chabardes, S.; Mitrofanis, J.; Pollak, P. Deep brain stimulation of the subthalamic nucleus for the treatment of Parkinson's disease. Lancet Neurol. 2009, 8, 67-81. [CrossRef]

6. Benhabbour, S.R.; Kovarova, M.; Jones, C.; Copeland, D.J.; Shrivastava, R.; Swanson, M.D.; Sykes, C.; Ho, P.T.; Cottrell, M.L.; Sridharan, A.; et al. Ultra-long-acting tunable biodegradable and removable controlled release implants for drug delivery. Nat. Commun. 2019, 10, 4324. [CrossRef] [PubMed]

7. Yang, Y.; Gao, W. Wearable and flexible electronics for continuous molecular monitoring. Chem. Soc. Rev. 2019, 48, 1465-1491. [CrossRef] [PubMed]

8. Kim, J.; Campbell, A.S.; De Ávila, B.E.-F.; Wang, J. Wearable biosensors for healthcare monitoring. Nat. Biotechnol. 2019, 37, 389-406. [CrossRef] [PubMed]

9. Humar, M.; Kwok, S.J.; Choi, M.; Yetisen, A.K.; Cho, S.; Yun, S.-H. Toward biomaterial-based implantable photonic devices. Nanophotonics 2017, 6, 414-434. [CrossRef]

10. Shin, J.; Liu, Z.; Bai, W.; Liu, Y.; Yan, Y.; Xue, Y.; Kandela, I.; Pezhouh, M.; MacEwan, M.R.; Huang, Y.; et al. Bioresorbable optical sensor systems for monitoring of intracranial pressure and temperature. Sci. Adv. 2019, 5, eaaw1899. [CrossRef] 
11. Parashurama, N.; O'Sullivan, T.D.; De La Zerda, A.; El Kalassi, P.; Cho, S.; Liu, H.; Teed, R.; Levy, H.; Rosenberg, J.; Cheng, Z.; et al. Continuous sensing of tumor-targeted molecular probes with a vertical cavity surface emit-ting laser-based biosensor. J. Biomed. Opt. 2012, 17, 117004. [CrossRef]

12. O'Sullivan, T.D.; Heitz, R.T.; Parashurama, N.; Barkin, D.B.; Wooley, B.A.; Gambhir, S.S.; Harris, J.S.; Levi, O. Real-time, continuous, fluorescence sensing in a freely-moving subject with an implanted hybrid VCSEL/CMOS biosensor. Biomed. Opt. Express 2013, 4, 1332-1341. [CrossRef] [PubMed]

13. Wang, J.; Dong, J. Optical Waveguides and Integrated Optical Devices for Medical Diagnosis, Health Monitoring and Light Therapies. Sensors 2020, 20, 3981. [CrossRef] [PubMed]

14. Robertson, C.; Evans, D.H.; Abrahamse, H. Photodynamic therapy (PDT): A short review on cellular mechanisms and cancer research applications for PDT. J. Photochem. Photobiol. B Biol. 2009, 96, 1-8. [CrossRef] [PubMed]

15. Siewert, B.; Stuppner, H. The photoactivity of natural products-An overlooked potential of phytomedicines? Phytomedicine 2019, 60, 152985. [CrossRef]

16. Huang, X.; El-Sayed, M.A. Plasmonic photo-thermal therapy (PPTT). Alex. J. Med. 2011, 47, 1-9. [CrossRef]

17. Hamblin, M.R. Mechanisms and applications of the anti-inflammatory effects of photobiomodulation. AIMS Biophys. 2017, 4, 337-361. [CrossRef]

18. Dong, J.; Xiong, D. Applications of Light Emitting Diodes in Health Care. Ann. Biomed. Eng. 2017, 45, 2509-2523. [CrossRef]

19. Bai, W.; Shin, J.; Fu, R.; Kandela, I.; Lu, D.; Ni, X.; Park, Y.; Liu, Z.; Hang, T.; Wu, D.; et al. Bioresorbable photonic devices for the spectroscopic characterization of physiological status and neural activity. Nat. Biomed. Eng. 2019, 3, 644-654. [CrossRef] [PubMed]

20. Bai, W.; Yang, H.; Ma, Y.; Chen, H.; Shin, J.; Liu, Y.; Yang, Q.; Kandela, I.; Liu, Z.; Kang, S.K.; et al. Flexible Transient Optical Waveguides and Surface-Wave Biosensors Constructed from Monocrystalline Silicon. Adv. Mater. 2018, 30, 1801584. [CrossRef] [PubMed]

21. Tao, H.; Kainerstorfer, J.M.; Siebert, S.M.; Pritchard, E.M.; Sassaroli, A.; Panilaitis, B.J.B.; Brenckle, M.A.; Amsden, J.J.; Levitt, J.; Fantini, S.; et al. Implantable, multifunctional, bioresorbable optics. Proc. Natl. Acad. Sci. USA 2012, 109, 19584-19589. [CrossRef]

22. Luker, G.D.; Luker, K.E. Optical Imaging: Current Applications and Future Directions. J. Nucl. Med. 2007, 49, 1-4. [CrossRef] [PubMed]

23. Humar, M.; Dobravec, A.; Zhao, X.; Yun, S.H. Biomaterial microlasers implantable in the cornea, skin, and blood. Optica 2017, 4, 1080-1085. [CrossRef] [PubMed]

24. Han, S.; Shin, G. Biodegradable Optical Fiber in a Soft Optoelectronic Device for Wireless Optogenetic Applications. Coatings 2020, 10, 1153. [CrossRef]

25. Fan, B.; Li, W. Miniaturized optogenetic neural implants: A review. Lab Chip 2015, 15, 3838-3855. [CrossRef] [PubMed]

26. Lu, D.; Yan, Y.; Deng, Y.; Yang, Q.; Zhao, J.; Seo, M.; Bai, W.; MacEwan, M.R.; Huang, Y.; Ray, W.Z.; et al. Bioresorbable Wireless Sensors as Temporary Implants for In Vivo Measurements of Pressure. Adv. Funct. Mater. 2020, 30, 2003754. [CrossRef]

27. Lu, D.; Yan, Y.; Avila, R.; Kandela, I.; Stepien, I.; Seo, M.; Bai, W.; Yang, Q.; Li, C.; Haney, C.R.; et al. Bioresorbable, Wireless, Passive Sensors as Temporary Implants for Monitoring Regional Body Temperature. Adv. Healthc. Mater. 2020, 9 , 2000942. [CrossRef]

28. Yu, K.J.; Kuzum, D.; Hwang, S.W.; Kim, B.H.; Juul, H.; Kim, N.H.; Won, S.M.; Chiang, K.; Trumpis, M.; Richardson, A.G.; et al Bioresorbable silicon electronics for transient spatiotemporal map-ping of electrical activity from the cerebral cortex. Nat. Mater. 2016, 15, 782-791. [CrossRef]

29. Mattina, A.; Mariani, S.; Paghi, A.; Corsi, M. Bioresorbable and Biodegradable Electronics and Photonics. In Proceedings of the 2020 IEEE Sensors, Rotterdam, The Netherlands, 25-28 October 2020.

30. Singh, R.; Bathaei, M.J.; Istif, E.; Beker, L. A Review of Bioresorbable Implantable Medical Devices: Materials, Fabrication, and Implementation. Adv. Healthc. Mater. 2020, 9, 2000790. [CrossRef] [PubMed]

31. La Mattina, A.A.; Mariani, S.; Barillaro, G. Bioresorbable Materials on the Rise: From Electronic Components and Physical Sensors to In Vivo Monitoring Systems. Adv. Sci. 2020, 7, 1902872. [CrossRef]

32. Onuki, Y.; Bhardwaj, U.; Papadimitrakopoulos, F.; Burgess, D.J. A Review of the Biocompatibility of Implantable Devices: Current Challenges to Overcome Foreign Body Response. J. Diabetes Sci. Technol. 2008, 2, 1003-1015. [CrossRef] [PubMed]

33. Morais, J.M.; Papadimitrakopoulos, F.; Burgess, D.J. Biomaterials/Tissue Interactions: Possible Solutions to Overcome Foreign Body Response. AAPS J. 2010, 12, 188-196. [CrossRef] [PubMed]

34. Lu, L.; Yang, Z.; Meacham, K.; Cvetkovic, C.; Corbin, E.A.; Vázquez-Guardado, A.; Xue, M.; Yin, L.; Boroumand, J.; Pakeltis, G.; et al. Biodegradable Monocrystalline Silicon Photovoltaic Microcells as Power Supplies for Transient Biomedical Implants. Adv. Energy Mater. 2018, 8, 1703035. [CrossRef]

35. Lu, D.; Liu, T.; Chang, J.; Peng, D.; Zhang, Y.; Shin, J.; Hang, T.; Bai, W.; Yang, Q.; Rogers, J.A. Transient Light-Emitting Diodes Constructed from Semiconductors and Transparent Conductors that Biodegrade Under Physiological Conditions. Adv. Mater. 2019, 31, e1902739. [CrossRef]

36. Shin., J.; Yan., Y.; Bai., W.; Xue, Y.; Gamble, P.; Tian, L.; Kandela, I.; Haney, C.R.; Spees, W.; Lee, Y.; et al. Bioresorbable pressure sensors protected with thermally grown silicon dioxide for the monitoring of chronic diseases and healing processes. Nat. Biomed. Eng. 2019, 3, 37-46. [CrossRef] 
37. Kang, S.-K.; Hwang, S.; Cheng, H.; Yu, S.; Kim, B.H.; Kim, J.-H.; Huang, Y.; Rogers, J.A. Dissolution Behaviors and Applications of Silicon Oxides and Nitrides in Transient Electronics. Adv. Funct. Mater. 2014, 24, 4427-4434. [CrossRef]

38. Kang, S.K.; Murphy, R.K.; Hwang, S.W.; Lee, S.M.; Harburg, D.V.; Krueger, N.A.; Shin, J.; Gamble, P.; Cheng, H.; Yu, S.; et al. Bioresorbable silicon electronic sensors for the brain. Nature 2016, 530, 71-76. [CrossRef]

39. Hwang, S.; Tao, H.; Kim, D.-H.; Cheng, H.; Song, J.-K.; Rill, E.; Brenckle, M.A.; Panilaitis, B.; Won, S.M.; Kim, Y.-S.; et al. A Physically Transient Form of Silicon Electronics. Science 2012, 337, 1640-1644. [CrossRef]

40. Lu, Q.; Hu, X.; Wang, X.; Kluge, J.A.; Lu, S.; Cebe, P.; Kaplan, D.L. Water-insoluble silk films with silk I structure. Acta Biomater. 2010, 6, 1380-1387. [CrossRef]

41. Kim, D.-H.; Kim, Y.-S.; Amsden, J.; Panilaitis, B.; Kaplan, D.L.; Omenetto, F.G.; Zakin, M.R.; Rogers, J.A. Silicon electronics on silk as a path to bioresorbable, implantable devices. Appl. Phys. Lett. 2009, 95, 133701. [CrossRef]

42. Mehrasa, M.; Asadollahi, M.A.; Ghaedi, K.; Salehi, H.; Arpanaei, A. Electrospun aligned PLGA and PLGA/gelatin nanofibers embedded with silica nanoparticles for tissue engineering. Int. J. Biol. Macromol. 2015, 79, 687-695. [CrossRef]

43. Park, P.I.P.; Jonnalagadda, S. Predictors of glass transition in the biodegradable poly-lactide and poly-lactide-co-glycolide polymers. J. Appl. Polym. Sci. 2006, 100, 1983-1987. [CrossRef]

44. Kopeinik, H.; Schennach, R.; Gallik, J.; Plank, H.; Friedel, B. Photodiodes based on wood pulp fiber networks. Cellulose 2015, 22, 3425-3434. [CrossRef]

45. Pataniya, P.M.; Sumesh, C.K. WS2 Nanosheet/Graphene Heterostructures for Paper-Based Flexible Photodetectors. ACS Appl. Nano Mater. 2020, 3, 6935-6944. [CrossRef]

46. Khanra, S.; Cipriano, T.; Lam, T.; White, T.A.; Fileti, E.E.; Alves, W.A.; Guha, S. Self-Assembled Peptide-Polyfluorene Nanocomposites for Biodegradable Organic Electronics. Adv. Mater. Interfaces 2015, 2, 1500265. [CrossRef]

47. Källrot, M.; Edlund, U.; Albertsson, A.-C. Covalent Grafting of Poly(l-lactide) to Tune the In Vitro Degradation Rate. Biomacromolecules 2007, 8, 2492-2496. [CrossRef] [PubMed]

48. Nazempour, R.; Zhang, Q.; Fu, R.; Sheng, X. Biocompatible and Implantable Optical Fibers and Waveguides for Biomedicine. Materials 2018, 11, 1283. [CrossRef]

49. Applegate, M.B.; Perotto, G.; Kaplan, D.L.; Omenetto, F.G. Biocompatible silk step-index optical waveguides. Biomed. Opt. Express 2015, 6, 4221-4227. [CrossRef]

50. Fujiwara, E.; Cabral, T.D.; Sato, M.; Oku, H.; Cordeiro, C.M.B. Agarose-based structured optical fiber. Sci. Rep. 2020, 10, 7035. [CrossRef]

51. Fu, R.X.; Luo, W.H.; Nazempour, R.; Tan, D.X.; Ding, H.; Zhang, K.Y.; Yin, L.; Guan, J.S.; Sheng, X. Implantable and Biode-gradable Poly(L-lactic acid) Fibers for Optical Neural Interfaces. Adv. Opt. Mater. 2018, 6, 1700941. [CrossRef]

52. Nizamoglu, S.; Gather, M.; Humar, M.; Choi, M.; Kim, S.; Kim, K.S.; Hahn, S.K.; Scarcelli, G.; Randolph, M.; Redmond, R.W.; et al. Bioabsorbable polymer optical waveguides for deep-tissue photomedicine. Nat. Commun. 2016, 7, 10374. [CrossRef] [PubMed]

53. Feng, J.; Zheng, Y.; Bhusari, S.; Villiou, M.; Pearson, S.; Del Campo, A. Printed Degradable Optical Waveguides for Guiding Light into Tissue. Adv. Funct. Mater. 2020, 30, 2004327. [CrossRef]

54. Hwang, S.; Park, G.; Edwards, C.; Corbin, E.A.; Kang, S.; Cheng, H.; Song, J.; Kim, J.; Yu, S.; Ng, J.; et al. Dissolution Chemistry and Biocompatibility of Single-Crystalline Silicon Nanomembranes and Associated Materials for Transient Electronics. ACS Nano 2014, 8, 5843-5851. [CrossRef] [PubMed]

55. Kang, S.-K.; Park, G.; Kim, K.; Hwang, S.; Cheng, H.; Shin, J.; Chung, S.; Kim, M.; Yin, L.; Lee, J.C.; et al. Dissolution Chemistry and Biocompatibility of Silicon- and Germanium-Based Semiconductors for Transient Electronics. ACS Appl. Mater. Interfaces 2015, 7, 9297-9305. [CrossRef]

56. Jung, Y.H.; Zhang, H.; Gong, S.; Ma, Z. High-performance green semiconductor devices: Materials, designs, and fabrication. Semicond. Sci. Technol. 2017, 32, 063002. [CrossRef]

57. Yin, L.; Cheng, H.; Mao, S.; Haasch, R.; Liu, Y.; Xie, X.; Hwang, S.; Jain, H.; Kang, S.-K.; Su, Y.; et al. Dissolvable Metals for Transient Electronics. Adv. Funct. Mater. 2014, 24, 645-658. [CrossRef]

58. Hwang, S.; Park, G.; Cheng, H.; Song, J.-K.; Kang, S.-K.; Yin, L.; Kim, J.-H.; Omenetto, F.G.; Huang, Y.; Lee, K.-M.; et al. 25th Anniversary Article: Materials for High-Performance Biodegradable Semiconductor Devices. Adv. Mater. 2014, 26, 1992-2000. [CrossRef]

59. Fang, H.; Zhao, J.; Yu, K.J.; Song, E.; Farimani, A.B.; Chiang, C.-H.; Jin, X.; Xue, Y.; Xu, D.; Du, W.; et al. Ultrathin, transferred layers of thermally grown silicon dioxide as biofluid barriers for biointegrated flexible electronic systems. Proc. Natl. Acad. Sci. USA 2016, 113, 11682-11687. [CrossRef]

60. You, C.; Zhao, H.; Guo, Q.; Mei, Y. Material strategies for on-demand smart transient electronics. MRS Bull. 2020, 45, 129-134. [CrossRef]

61. Kwon, K.Y.; Lee, J.S.; Ko, G.-J.; Sunwoo, S.H.; Lee, S.; Jo, Y.J.; Choi, C.H.; Hwang, S.-W.; Kim, T.-I. Biosafe, Eco-Friendly Levan Polysaccharide toward Transient Electronics. Small 2018, 14, e1801332. [CrossRef]

62. Rüegg, M.; Blum, R.; Boero, G.; Brugger, J. Biodegradable Frequency-Selective Magnesium Radio-Frequency Microresonators for Transient Biomedical Implants. Adv. Funct. Mater. 2019, 29, 1903051. [CrossRef]

63. Wu, C.; Jiang, J.; Guo, H.; Pu, X.; Liu, L.; Ding, W.; Kohl, P.A.; Wang, Z.L. Sunlight-Triggerable Transient Energy Harvester and Sensors Based on Triboelectric Nanogenerator Using Acid-Sensitive Poly(phthalaldehyde). Adv. Electron. Mater. 2019, 5 , 1900725. [CrossRef] 
64. Sparta, D.R.; Stamatakis, A.M.; Phillips, J.L.; Hovelsø, N.; Van Zessen, R.; Stuber, G.D. Construction of implantable optical fibers for long-term optogenetic manipulation of neural circuits. Nat. Protoc. 2011, 7, 12-23. [CrossRef] [PubMed]

65. Sykes, E.A.; Albanese, A.; Chan, W.C.W. Biophotonics Implantable waveguides. Nat. Photonics 2013, 7, 940-941. [CrossRef]

66. Qiao, X.; Qian, Z.; Li, J.; Sun, H.; Han, Y.; Xia, X.; Zhou, J.; Wang, C.; Wang, Y.; Wang, C. Synthetic Engineering of Spider Silk Fiber as Implantable Optical Waveguides for Low-Loss Light Guiding. ACS Appl. Mater. Interfaces 2017, 9, 14665-14676. [CrossRef] [PubMed]

67. Gierej, A.; Geernaert, T.; Van Vlierberghe, S.; Dubruel, P.; Thienpont, H.; Berghmans, F. Challenges in the Fabrication of Biode-gradable and Implantable Optical Fibers for Biomedical Applications. Materials 2021, 14, 1972. [CrossRef]

68. Wu, C.; Liu, X.; Ying, Y. Soft and Stretchable Optical Waveguide: Light Delivery and Manipulation at Complex Biointerfaces Creating Unique Windows for On-Body Sensing. ACS Sens. 2021, 6, 1446-1460. [CrossRef]

69. Scheggi, A.M.; Migna, A.G. Optical fiber biosensing. Opt. News 1989, 15, 28-34. [CrossRef]

70. Mitsui, K.; Handa, Y.; Kajikawa, K. Optical fiber affinity biosensor based on localized surface plasmon resonance. Appl. Phys. Lett. 2004, 85, 4231-4233. [CrossRef]

71. Sridharan, A.; Rajan, S.D.; Muthuswamy, J.; Rajan, S.D. Long-term changes in the material properties of brain tissue at the implant-tissue interface. J. Neural Eng. 2013, 10, 066001. [CrossRef]

72. Grosenick, L.; Marshel, J.; Deisseroth, K. Closed-Loop and Activity-Guided Optogenetic Control. Neuron 2015, 86, 106-139. [CrossRef]

73. Podrazký, O.; Peterka, P.; Kašík, I.; Vytykáčová, S.; Proboštová, J.; Mrázek, J.; Kuneš, M.; Závalová, V.; Radochová, V.; Lyutakov, O.; et al. In vivo testing of a bioresorbable phosphate-based optical fiber. J. Biophotonics 2019, 12, e201800397. [CrossRef]

74. Hohlfeld, D.; Zappe, H. Thermal and Optical Characterization of Silicon-Based Tunable Optical Thin-Film Filters. J. Microelectromechanical Syst. 2007, 16, 500-510. [CrossRef]

75. Wei, Q.; Qi, H.; Luo, W.; Tseng, D.; Ki, S.J.; Wan, Z.; Goöroöcs, Z.; Bentolila, L.A.; Wu, T.; Sun, R.; et al. Fluorescent Imaging of Single Nanoparticles and Viruses on a Smart Phone. Am. Chem. Soc. 2013, 7, 9147. [CrossRef] [PubMed]

76. Guo, T.; Liu, F.; Guan, B.-O.; Albert, J. [Invited] Tilted fiber grating mechanical and biochemical sensors. Opt. Laser Technol. 2016, 78, 19-33. [CrossRef]

77. Lee, C.H.; Kim, J.-H.; Zou, C.; Cho, I.S.; Weisse, J.M.; Nemeth, W.; Wang, Q.; Van Duin, A.C.T.; Kim, T.-S.; Zheng, X. Peel-and-Stick: Mechanism Study for Efficient Fabrication of Flexible/Transparent Thin-film Electronics. Sci. Rep. 2013, 3, 1-6. [CrossRef]

78. Liu, C.B.; Zhang, Q.Y.; Wang, D.; Zhao, G.L.; Cai, X.; Li, L.Z.; Ding, H.; Zhang, K.Y.; Wang, H.C.; Kong, D.Y.; et al. High Performance, Biocompatible Dielectric Thin-Film Optical Filters Integrated with Flexible Substrates and Microscale Optoelectronic Devices. Adv. Opt. Mater. 2018, 6, 1800146. [CrossRef]

79. Meitl, M.A.; Zhu, Z.; Kumar, V.; Lee, K.J.; Feng, X.; Huang, Y.Y.; Adesida, I.; Nuzzo, R.G.; Rogers, J.A. Transfer printing by kinetic control of adhesion to an elastomeric stamp. Nat. Mater. 2005, 5, 33-38. [CrossRef]

80. Guo, Q.; Zhang, M.; Xue, Z.; Wang, G.; Chen, D.; Cao, R.; Huang, G.; Mei, Y.; Di, Z.; Wang, X. Deterministic Assembly of Flexible Si/Ge Nanoribbons via Edge-Cutting Transfer and Printing for van der Waals Heterojunctions. Small 2015, 11, 4140-4148. [CrossRef]

81. Guo, Q.L.; Zhang, M.; Xue, Z.Y.; Ye, L.; Wang, G.; Huang, G.S.; Mei, Y.F.; Wang, X.; Di, Z.F. Three dimensional strain distribu-tion of wrinkled silicon nanomembranes fabricated by rolling-transfer technique. Appl. Phys. Lett. 2013, 103, 264102. [CrossRef]

82. Chen, Y.; Guo, Q.; Huang, G.; Li, G.; Wang, L.; Tian, Z.; Qin, Y.; Di, Z.; Mei, Y. Multifunctional Nanocracks in Silicon Nanomembranes by Notch-Assisted Transfer Printing. ACS Appl. Mater. Interfaces 2018, 10, 25644-25651. [CrossRef] [PubMed]

83. Bai, W.; Irie, M.; Liu, Z.; Luan, H.; Franklin, D.; Nandoliya, K.; Guo, H.; Zang, H.; Weng, Y.; Lu, D.; et al. Bioresorbable Multilayer Photonic Cavities as Temporary Implants for Tether-Free Measurements of Regional Tissue Temperatures. BME Front. 2021, $2021,1-14$. [CrossRef]

84. Sheinman, V.; Rudnitsky, A.; Toichuev, R.; Eshiev, A.; Abdullaeva, S.; Egemkulov, T.; Zalevsky, Z. Implantable photonic devices for improved medical treatments. J. Biomed. Opt. 2014, 19, 108001. [CrossRef]

85. Ohta, J.; Tagawa, A.; Kobayashi, T.; Noda, T.; Sasagawa, K.; Tokuda, T. Implantable Distributed Biomedical Photonic Devices. Sens. Mater. 2011, 23, 369-379.

86. Calabrese, E.J.; Baldwin, L.A. U-Shaped Dose-Responses in Biology, Toxicology, and Public Health. Annu. Rev. Public Health 2001, 22, 15-33. [CrossRef]

87. Huang, Y.-Y.; Chen, A.C.-H.; Carroll, J.D.; Hamblin, M.R. Biphasic Dose Response in Low Level Light Therapy. Dose-Response 2009, 7, 358-383. [CrossRef]

88. Hagen, J.A.; Li, W.; Steckl, A.; Grote, J.G. Enhanced emission efficiency in organic light-emitting diodes using deoxyribonucleic acid complex as an electron blocking layer. Appl. Phys. Lett. 2006, 88, 171109. [CrossRef]

89. Gomez, E.F.; Venkatraman, V.; Grote, J.G.; Steckl, A.J. Exploring the Potential of Nucleic Acid Bases in Organic Light Emitting Diodes. Adv. Mater. 2015, 27, 7552-7562. [CrossRef]

90. Jürgensen, N.; Ackermann, M.; Marszalek, T.; Zimmermann, J.; Morfa, A.J.; Pisula, W.; Bunz, U.H.F.; Hinkel, F.; Hernandez-Sosa, G. Solution-Processed Bio-OLEDs with a Vitamin-Derived Riboflavin Tetrabutyrate Emission Layer. ACS Sustain. Chem. Eng. 2017, 5, 5368-5372. [CrossRef]

91. Ghosh, A.P.; Gerenser, L.J.; Jarman, C.M.; Fornalik, J.E. Thin-film encapsulation of organic light-emitting devices. Appl. Phys. Lett. 2005, 86, 223503. [CrossRef] 
92. Huang, X.; Wang, D.; Yuan, Z.; Xie, W.; Wu, Y.; Li, R.; Zhao, Y.; Luo, D.; Cen, L.; Chen, B.; et al. A Fully Biodegradable Battery for Self-Powered Transient Implants. Small 2018, 14, e1800994. [CrossRef] [PubMed]

93. Tian, W.; Li, Y.; Zhou, J.; Wang, T.; Zhang, R.; Cao, J.; Luo, M.; Li, N.; Zhang, N.; Gong, H.; et al. Implantable and Biodegradable Micro-Supercapacitor Based on a Superassembled Three-Dimensional Network Zn@PPy Hybrid Electrode. ACS Appl. Mater. Interfaces 2021, 13, 8285-8293. [CrossRef] [PubMed]

94. Jiang, W.; Li, H.; Liu, Z.; Li, Z.; Tian, J.; Shi, B.; Zou, Y.; Ouyang, H.; Zhao, C.; Zhao, L.; et al. Fully Bioabsorbable NaturalMaterials-Based Triboelectric Nanogenerators. Adv. Mater. 2018, 30, e1801895. [CrossRef] [PubMed]

95. Sun, J.; Guo, H.; Ribera, J.; Wu, C.; Tu, K.; Binelli, M.; Panzarasa, G.; Schwarze, F.; Wang, Z.L.; Burgert, I. Sustainable and Biode-gradable Wood Sponge Piezoelectric Nanogenerator for Sensing and Energy Harvesting. Appl. ACS Nano 2020, 14, 14665-14674. [CrossRef]

96. Manoufali, M.; Bialkowski, K.; Mohammed, B.; Abbosh, A. Wireless Power Link Based on Inductive Coupling for Brain Im-plantable Medical Devices. IEEE Antennas Wirel. Propag. Lett. 2018, 17, 160-163. [CrossRef]

97. Guo, Q.; Koo, J.; Xie, Z.; Avila, R.; Yu, X.; Ning, X.; Zhang, H.; Liang, X.; Kim, S.B.; Yan, Y.; et al. A Bioresorbable Magnetically Coupled System for Low-Frequency Wireless Power Transfer. Adv. Funct. Mater. 2019, 29, 1905451. [CrossRef]

98. Huang, X.; Wang, L.; Wang, H.; Zhang, B.; Wang, X.; Stening, R.Y.Z.; Sheng, X.; Yin, L. Materials Strategies and Device Architectures of Emerging Power Supply Devices for Implantable Bioelectronics. Small 2020, 16, e1902827. [CrossRef]

99. Sheng, H.; Zhang, X.; Liang, J.; Shao, M.; Xie, E.; Yu, C.; Lan, W. Recent Advances of Energy Solutions for Implantable Bioelectronics. Adv. Healthc. Mater. 2021, 2100199. [CrossRef]

100. Sheng, X.; Wang, S.; Yin, L. Flexible, Stretchable, and Biodegradable Thin-Film Silicon Photovoltaics. In Advances in Silicon Solar Cells; Springer Science and Business Media LLC: Berlin, Germany, 2018; pp. 161-175.

101. Ramirez, S.; Liu, X.; Macdonald, C.J.; Moffa, A.; Zhou, J.; Redondo, R.L.; Tonegawa, S. Activating positive memory engrams suppresses depression-like behaviour. Nat. Cell Biol. 2015, 522, 335-339. [CrossRef] [PubMed]

102. Nussinovitch, U.; Gepstein, L. Optogenetics for in vivo cardiac pacing and resynchronization therapies. Nat. Biotechnol. 2015, 33, 750-754. [CrossRef]

103. Qi, C.; Varga, S.; Oh, S.-J.; Lee, C.J.; Lee, D. Optogenetic Rescue of Locomotor Dysfunction and Dopaminergic Degeneration Caused by Alpha-Synuclein and EKO Genes. Exp. Neurobiol. 2017, 26, 97-103. [CrossRef]

104. Zhang, H.; Zhao, H.; Zeng, C.; Van Dort, C.; Faingold, C.L.; Taylor, N.E.; Solt, K.; Feng, H.-J. Optogenetic activation of 5-HT neurons in the dorsal raphe suppresses seizure-induced respiratory arrest and produces anticonvulsant effect in the DBA/1 mouse SUDEP model. Neurobiol. Dis. 2018, 110, 47-58. [CrossRef] [PubMed]

105. Bansal, A.; Yang, F.; Xi, T.; Zhang, Y.; Ho, J.S. In vivo wireless photonic photodynamic therapy. Proc. Natl. Acad. Sci. USA 2018, 115, 1469-1474. [CrossRef]

106. Yang, T.D.; Park, K.; Kim, H.-J.; Im, N.-R.; Kim, B.; Kim, T.; Seo, S.; Lee, J.-S.; Kim, B.-M.; Choi, Y.; et al. In vivo photothermal treatment with real-time monitoring by optical fiber-needle array. Biomed. Opt. Express 2017, 8, 3482-3492. [CrossRef] [PubMed]

107. de Freitas, L.F.; Hamblin, M.R. Proposed Mechanisms of Photobiomodulation or Low-Level Light Therapy. IEEE J. Sel. Top. Quantum Electron. 2016, 22, 7000417. [CrossRef] [PubMed]

108. Jiang, Y.; Qi, W.; Zhang, Q.; Liu, H.; Zhang, J.; Du, N.; Nazempour, R.; Su, Y.; Fu, R.; Zhang, K.; et al. Green Light-Based Photobiomodulation with an Implantable and Biodegradable Fiber for Bone Regeneration. Small Methods 2020, 4, 1900879. [CrossRef] 